Pruszyński Jacek J., Cianciara Dorota, Engel Janusz, Zgliczyński Wojciech S. Negative opinion on work as variable of career shift among doctors in Poland. Are we running out of doctors in post-COVID times? Journal of Education, Health and Sport. 2022;12(2):174-184. eISSN 2391-8306. DOI http://dx.doi.org/10.12775/JEHS.2022.12.02.020

https://apcz.umk.pl/JEHS/article/view/JEHS.2022.12.02.020

https://zenodo.org/record/6250703

The journal has had 40 points in Ministry of Education and Science of Poland parametric evaluation. Annex to the announcement of the Minister of Education and Science of December 21, 2021. No. 32343. Has a Journal's Unique Identifier: 201159. Scientific disciplines assigned: Physical Culture Sciences (Field of Medical sciences and health sciences); Health Sciences (Field of Medical Sciences and Health Sciences).

Punkty Ministerialne z 2019 - aktualny rok 40 punktów. Zalącrnik do komunikatu Ministra Edukacji i Nauki z dnia 21 grudnia 2021 r. Lp. 32343. Posiada Unikatowy Identyfikator Czasopisma: 201159. Przypisane dyscypliny naukowe:Nauki o kulturze fizycznej (Dziedzina nauk medycznych i nauk o zdrowiu); Nauki o zdrowiu (Dziedzina nauk medycznych i nauk o zdrowiu).

(c) The Authors 2022;

This article is published with open access at Licensee Open Journal Systems of Nicolaus Copernicus University in Torun, Poland

Open Access. This article is distributed under the terms of the Creative Commons Attribution Noncommercial License which permits any noncommercial use, distribution, and reproduction in any medium, provided the original author (s) and source are credited. This is an open access article licensed under the terms of the Creative Commons Attribution Non commercial license Share alike. (http://creativecommons.org/licenses/by-nc-sa/4.0/) which permits unrestricted, non commercial use, distribution and reproduction in any medium, provided the work is properly cited.

Received: 02.02.2022. Revised: 20.02.2022. Accepted: 23.02.2022.

Negative opinion on work as variable of career shift among doctors in Poland. Are we running out of doctors in post-COVID times?

Negatywna opinia o pracy jako zmienna chęci zmiany zawodu przez lekarzy w Polsce.

Czy zabraknie nam lekarzy po pandemii COVID-19?

Jacek J. Pruszyński ORCID: 0000-0003-2123-6488

Affiliation

Department of Geriatrics and Gerontology

School of Public Health Center of Postgraduate Medical Education

Kleczewska 61/63

01-826 Warszawa

e-mail: jacek.pruszynski@cmkp.edu.pl

Dorota Cianciara ORCID: 0000-0002-0318-8649

Affiliation

Department of Epidemiology and Health Promotion School of Public Health

Center of Postgraduate Medical Education

Kleczewska 61/63

01-826 Warszawa

e-mail: dorota.cianciara@cmkp.edu.pl

Department of Health Promotion and NCD Prevention

National Institute of Public Health NIH - National Research Institute

Chocimska 24

00-791 Warszawa

e-mail: dcianciara@pzh.gov.pl

\title{
Janusz Engel
}

Affiliation

former statistics in School of Public Health Center of Postgraduate Medical Educatiom

Kleczewska $61 / 63$

01-826 Warszawa 
e-mail: jengel@tlen.pl

Wojciech S. Zgliczyński ORCID: 0000-0003-0054-4860

Affiliation

Department of Geriatrics and Gerontology

School of Public Health Center of Postgraduate Medical Education

Kleczewska 61/63

01-826 Warszawa

e-mail:wzgliczynski2@cmkp.edu.pl

\begin{abstract}
Introduction and objective. Work conditions and evaluation, stress, professional burnout among doctors are the subject of analyzes and research in Poland. Less attention is focused on the problem of leaving the profession. The aim of the study was to determine the relationship between the socio-demographic and professional characteristics of doctors and the subjective assessment of their current work and the willingness to undertake an alternative career.
\end{abstract}

Material and methods. A survey was conducted among 315 doctors attending courses at the Medical Center of Postgraduate Education in 2018/19. The questionnaire consisted of 14 questions. The dependent variable was the declaration of willingness to change the medical profession to another, if it was possible to maintain income. The explanatory variables were socio-demographic and professional characteristics: gender, age and the performance of surgical and non-surgical specialties as well as subjective assessment of current professional work in terms of 10 attributes of a doctor's work. The analysis used the Pearson $\chi 2$ test, Spearman's rank correlation coefficient and clustering.

Results. The vast majority of doctors admitted that their work was interesting $(95.9 \%)$, but nervous $(90.5 \%)$ and threatening $(77.8 \%)$. Nervousness was significantly more often indicated by young doctors. $18.1 \%$ of physicians declared their willingness to change their profession. The desire to change profession was most strongly associated with the opinion that work was unpleasant and disgusting.

Conclusions. More doctors reported the disadvantages of their work than its advantages. Every fifth declared a willingness to change their profession. The willingness to change profession was strongly related to the overall negative assessment of one's own work. Presumably, as a result of the COVID-19 pandemic, more and more doctors will evaluate their work negatively, which may prompt them to change their profession. This situation requires monitoring the impact of COVID-19 on the workforce and taking remedial measures.

Key words: physicians, employment, professionalism, trends 


\section{WPROWADZENIE I CEL PRACY}

Systemy zdrowotne mogą spełniać swoje zadania tylko dzięki pracownikom właściwym osobom, z właściwymi umiejętnościami, czynnym we właściwym czasie oraz miejscu i wykonujących właściwą pracę. Taką, która dąży do osiągnięcia możliwie najwyższego standardu zdrowia, responsywności, a także poprawy powszechnego zabzpieczenia zdrowotnego (universal health coverag) oraz rozwoju społecznej odporności na czynniki szkodliwe (community resilience) [1].

Globalne zainteresowanie kadrą systemu zdrowia nie ogranicza się do kwestii dostępności, osiągalności, akceptowalności i jakości (availability, accessibility, acceptability and quality). Podkreślane są też rosnące wymagania stawiane pracownikom. Dotyczą one głównie intensyfikacji pracy oraz samodzielności przy planowaniu zadań, rozwoju zawodowego i kariery [2]. Intensywność pracy w ochronie zdrowia, także lekarzy, można ocenić przy uwzględnieniu aspektów specyficznych dla tej pracy (np. niepewność wyników) bądź niespecyficznych, charakteryzujących różne rodzaje pracy. Według tej ostatniej metody, wykorzystanej w 2015 r. w Sixth European Working Conditions Survey, w 28 krajach UE intensywność pracy $\mathrm{w}$ systemie zdrowia była oceniona jako większa niż $\mathrm{w}$ rolnictwie, przemyśle, budownictwie, handlu i hotelarstwie, transporcie, usługach finansowych, administracji publicznej i edukacji pod względem np.: braku wystarczającej ilości czasu, ukrywania emocji, zmagania się z rozgniewanymi klientami oraz sytuacji wywołujących niepokój [3]. Czynniki te rzutują na jakość życia pracowników - zdrowie, samopoczucie, satysfakcję zawodową, stres, wypalenie, chęć migracji za granicę albo rezygnację z pracy klinicznej i zmianę drogi kariery. Promieniują na doświadczenia pacjentów i mają wpływ na bezpieczeństwo i jakość opieki. Mają związek z zasobami finansowymi systemu zdrowia, oszczędnościami i cięciami kosztów opieki, drenażem mózgów i krótkowzroczną polityką kadrową. Powinny być impulsem do tworzenia strategii dotyczących kształcenia, zatrudniania, rozlokowania oraz utrzymania kadry w zawodzie. Warto zauważyć, że w piśmiennictwie są informacje, że wyższe poziomy wydatków na opiekę zdrowotną niekoniecznie poprawiają satysfakcję lekarzy [4]. Satysfakcja zaś może być czynnikiem ochronnym przed stresem wynikającym z pracy [5]. Pokazuje to złożoność procesów oddziałujących na warunki, wyniki i ocenę pracy w systemie.

Rzeczywiste, nie deklaratywne, odejście od pracy klinicznej i zmiana ścieżki kariery wśród części lekarzy jest zjawiskiem nieuniknionym i dostrzeganym. O fluktuacjach kariery dyskutowano jeszcze przed globalnym kryzysem zdrowotnym związanym z COVID-19. Obecnie anglojęzyczny Internet obfituje we wskazówki na temat alternatywnych zajęć zawodowych, w których lekarze mogą dyskontować swoje wykształcenie. Niemniej badania na temat uwarunkowań rzeczywistej zmiany kariery są rzadkie, co wynika m.in. z problemów związanych z doborem grupy badawczej [6]. Więcej wiadomo o skali deklaracji porzucenia zawodu. W 2021 r. co piąty (22\%) lekarz w USA rozważał odejście od pracy klinicznej, głównie z powodu wypalenia zawodowego niezwiązanego z COVID-19 [7] natomiast w Polsce $11 \%$ rezydentów, $6 \%$ specjalistów i 9\% stażystów chciałoby odejść z zawodu w związku z epidemią [8].

Zasadniczo, przyczyny chęci zmiany kariery tkwią w mylnej decyzji dotyczącej wyboru przyszłego zawodu, negatywnej ocenie aktualnie wykonywanej pracy oraz zmianach w sytuacji osobistej, zdrowotnej i życiowej. Australian Medical Association (Victoria) wymienia aż 18 powodów, które skłaniają lekarzy do zmiany kariery, podkreślając jednocześnie, że są to zaledwie przykłady motywacji [9]. Zjawiska zmiany zawodu nie należy mylić ze zmianą miejsca pracy, co jest częściej spotykane.

Problem warunków i oceny pracy, stresu, wypalenia zawodowego wśród lekarzy w Polsce jest coraz częściej przedmiotem analiz i badań $[10,11,12,13,14]$. Na podstawie badań Naczelnej Izby Lekarskiej (NIL) z 2018 r. wiadomo np., że 15\% badanych lekarzy (N=2577) 
źle oceniało swoją pracę [15]. Zdecydowanie mniej uwagi od strony badawczej poświęca się problemowi odejścia od zawodu. Jeszcze mniej uwagi skupia się na stronie praktycznej, tj. strategiom przeciwdziałania tym problemom. Celem badania było określenie związku między cechami społeczno-demograficzno-zawodowymi lekarzy i subiektywną oceną ich aktualnej pracy zawodowej a chęcią podjęcia kariery alternatywnej (alternate career). O ile nam wiadomo jest to pierwsze krajowe badanie na ten temat.

\section{MATERIAL I METODY}

Badaniem ankietowym objęto lekarzy uczestniczących w kursach organizowanych przez Szkołę Zdrowia Publicznego Centrum Medycznego Kształcenia Podyplomowego w roku akademickim 2018/2019. Udział w kursach był związany z odbywaniem szkolenia specjalizacyjnego w różnych specjalnościach lekarskich. Uczestnicy pochodzili ze wszystkich województw w Polsce. W badaniu wzięło udział 315 osób (wskaźnik realizacji próby wyniósł 82,9\%) z zachowaniem anonimowości odpowiedzi i dobrowolności udziału.

Kwestionariusz ankiety składał się 14 pytań zamkniętych, został sprawdzony w pilotażu i skorygowany. Zmienną objaśnianą była deklaracja chęci zmiany zawodu lekarza na inny w okolicznościach „tu i teraz” (the here and now), jeśli tylko byłoby to możliwe, przy utrzymaniu tych samych dochodów. Respondenci wypowiadali się na ten temat na skali Likerta. Zmiennymi objaśniającymi były cechy społeczno-demograficzno-zawodowe, tj. płeć, wiek i rodzaj wykonywanej specjalności lekarskiej z podziałem na zabiegową i niezabiegową (Tab.1) oraz subiektywna ocena aktualnej pracy zawodowej respondentów w aspekcie 10 atrybutów.

Tabela 1. Charakterystyka społeczno-demograficzna i zawodowa respondentów

\begin{tabular}{|l|l|l|}
\hline Zmienna & N & $\%$ \\
\hline Płeć & 125 & \multicolumn{2}{l|}{} \\
\hline Mężczyzna & 190 & 39.7 \\
\hline Kobieta & \multicolumn{2}{l|}{} \\
\hline Wiek & 193 & 60.3 \\
\hline 24-30 lat & 96 & 61.3 \\
\hline $31-45$ lat & 26 & 30.4 \\
\hline 46 i więcej lat & \multicolumn{2}{|l|}{} \\
\hline Rodzaj specjalności lekarskiej & 262 & 8.3 \\
\hline Niezabiegowa & 53 & 16.8 \\
\hline Zabiegowa & & \\
\hline
\end{tabular}

W fazie przygotowawczej, w celu operacjonalizacji zmiennej dotyczącej subiektywnej oceny aktualnej pracy zawodowej poproszono 60 lekarzy, uczestników kursów nieobjętych niniejszym badaniem, o podanie 10 przymiotników najlepiej opisujących aktualną pracę lekarza $\mathrm{w}$ Polsce, zarówno $\mathrm{z}$ dobrej jak złej strony, wyjaśnienie znaczenia tych przymiotników oraz uzgodnienie opinii. Na opracowanej w ten sposób liście atrybutów pracy lekarza znalazły się:

1. Atrakcyjna, pociągająca, korzystna, intratna, kusząca.

2. Interesująca, zajmująca, ciekawa, wciągająca, nietuzinkowa.

3. Uspokajająca, lubiana, kojąca, dająca zadowolenie, wyciszająca.

4. Odprężająca, przyjemna, spokojna, relaksująca, rozluźniająca.

5. Gorączkowa, pośpieszna, pełna zamętu, chaotyczna, bezplanowa.

6. Nerwowa, wzburzająca, niepokojąca, stresująca, niespokojna. 
7. Niebezpieczna, szkodliwa, niszcząca, nieprzyjazna, pełna niepewności.

8. Zagrażająca, ryzykowna, karkołomna, niepokojąca, ciężka.

9. Nieprzyjemna, nielubiana, dokuczliwa, niesatysfakcjonująca, przykra.

10. Odrażająca, zniechęcająca, zła, paskudna, odpychająca.

Atrybuty 1-4 obrazują zalety, a 5-10 wady pracy zawodowej lekarza. Respondenci niniejszego badania byli proszeni o wyrażenie opinii o swojej pracy zawodowej w aspekcie tych atrybutów na skali Likerta mając możliwość wyjaśnia tych cech przez ankietera. W analizie utworzono sumaryczny indeks oceny pracy zawodowej. Wartość tego indeksu waha się w granicach 0-10. W przypadku potwierdzenia wszystkich zalet, tj. atrybutów 1-4, oraz zaprzeczenia wszystkim wadom, tj. atrybutom 5-10, indeks ten osiąga górny próg, tj. wynosi 10, co pokazuje całościowo pozytywną ocenę aktualnej pracy zawodowej. Można powiedzieć, że pokazuje też stan optymalny i pożądany, w którym ocena pracy jest na najwyższym możliwym poziomie. Indeks o wartości zero pokazuje całościowo negatywną ocenę pracy. W badanej grupie wyróżniono 3 zbiory respondentów z wartością indeksu 0-2, 3-4 oraz 5-10.

$\mathrm{W}$ analizie statystycznej wykorzystano test $\chi^{2}$ Pearsona oraz współczynnik korelacji rang Spearmana. Wykorzystano analizę skupień (klasteryzację) i wyróżniono 3 podgrupy respondentów (A, B, C) według częstości chęci zmiany zawodu. W obliczeniach przyjęto poziom istotności $\mathrm{p}<0.05$ jako znamienny statystycznie.

\section{WYNIKI}

Ocena aktualnej pracy zawodowej. Zdecydowana większość respondentów potwierdziła, że ich praca jest interesująca, ale zarazem nerwowa, zagrażająca i gorączkowa (Tab. 2).

Tabela 2. Ocena aktualnej pracy zawodowej według atrybutu

\begin{tabular}{|c|c|c|c|c|c|c|}
\hline \multicolumn{2}{|c|}{ Atrybuty pracy zawodowej lekarza } & \multicolumn{5}{|c|}{ Ocena pracy } \\
\hline & & \multirow{2}{*}{\multicolumn{2}{|c|}{ Tak }} & \multirow{2}{*}{\multicolumn{2}{|c|}{$\begin{array}{l}\text { Trudno powiedzieć } \\
\text { (Neutral) }\end{array}$}} & \multirow{3}{*}{\begin{tabular}{|l|}
$\mathrm{Nie}$ \\
$\mathrm{N}$
\end{tabular}} \\
\hline & & & & & & \\
\hline & & $\mathrm{N}$ & $\%$ & $\mathrm{~N}$ & $\%$ & \\
\hline \multicolumn{7}{|c|}{ Zalety pracy lekarza } \\
\hline 1 & Atrakcyjna & 180 & 57.1 & 57 & 18.1 & 78 \\
\hline 2 & Interesująca & 302 & 95.9 & 7 & 2.2 & 6 \\
\hline 3 & Uspokajająca & 7 & 2.2 & 23 & 7.3 & 285 \\
\hline 4 & Odprężająca & 13 & 4.1 & 15 & 4.8 & 287 \\
\hline \multicolumn{7}{|c|}{ Wady pracy lekarza } \\
\hline 5 & Gorączkowa & 240 & 76.2 & 36 & 11.4 & 39 \\
\hline 6 & Nerwowa & 285 & 90.5 & 12 & 3.8 & 18 \\
\hline 7 & Niebezpieczna & 199 & 63.2 & 49 & 15.5 & 67 \\
\hline 8 & Zagrażająca & 245 & 77.8 & 29 & 9.2 & 41 \\
\hline 9 & Nieprzyjemna & 54 & 17.1 & 63 & 20.0 & 198 \\
\hline 10 & Odrażająca & 13 & 4.1 & 45 & 14.3 & 257 \\
\hline
\end{tabular}

Tak - suma odpowiedzi "zdecydowanie tak" i "raczej tak"; nie - suma odpowiedzi "zdecydowanie nie" i "raczej nie"

Płeć nie wykazywała związku z oceną pracy. Najmłodsi respondenci, w wieku do 30 lat, istotnie częściej niż starsi zgadzali się z tym, że ich praca jest nerwowa $\left(\chi^{2}=6.345, \mathrm{df}=2\right.$, $\mathrm{p}<0.042)$ oraz nieprzyjemna $\left(\chi^{2}=6.051\right.$, df $\left.=2, p<0.049\right)$. Respondenci pracujący $w$ specjalizacjach zabiegowych, istotnie częściej niż pracujący w niezabiegowych, potwierdzali, że ich praca jest odprężająca $\left(\chi^{2}=7.966, \mathrm{df}=2, \mathrm{p}<0.019\right)$. 
W analizie korelacji rang Spearmana wykazano, że największa siła związku $(\mathrm{p}<0.001)$ wystąpiła przy jednoczesnym potwierdzeniu atrybutów: gorączkowa-nerwowa (rho $=0.463$ ), gorączkowa-niebezpieczna (rho $=0.413$ ), niebezpieczna-ryzykowna (rho $=0.4$ ), niebezpieczna-nerwowa $($ rho $=0.393)$ oraz goraczkowa-ryzykowna $($ rho $=0.327)$.

Chęć zmiany zawodu. Połowa badanych (50.5\%) raczej lub zdecydowanie nie chciałaby zmienić zawodu na inny. Jednak niemal co piaty (18.1\%) deklarował chęć zmiany zawodu, gdyby nie było z tym problemów, w tym finansowych (Tab. 3). Nie stwierdzono statystycznie istotnej zależności między cechami społeczno-demograficznymi oraz zawodowymi, tj. praktykowaną specjalnością a chęcią zmiany zawodu.

Tabela 3. Chęć zmiany zawodu

\begin{tabular}{|l|l|}
\hline Chęć zmiany zawodu & Deklaracja \\
\cline { 2 - 2 } & $\mathrm{N}$ \\
\hline Zdecydowanie tak & 18 \\
\hline Raczej tak & 39 \\
\hline Trudno powiedzieć & 99 \\
\hline Raczej nie & 84 \\
\hline Zdecydowanie nie & 75 \\
\hline Razem & 315 \\
\hline
\end{tabular}

Za pomocą analizy skupień wyróżniono 3 klastry, tj. podgrupy respondentów według częstości chęci zmiany zawodu, przy czym częstość ta była największa w grupie A i najmniejsza w $\mathrm{C}$ (Tab. 4).

Tabela 4. Chęć zmiany zawodu w podgrupach

\begin{tabular}{|l|l|l|l|}
\hline \multirow{2}{*}{$\begin{array}{l}\text { Chęć zawodu } \\
\text { zak }\end{array}$} & \multicolumn{4}{|l|}{ Deklaracja w podgrupach (\%) } \\
\cline { 2 - 4 } & $\mathrm{A}(\mathrm{N}=94)$ & $\mathrm{B}(\mathrm{N}=153)$ & $\mathrm{C}(\mathrm{N}=68)$ \\
\hline Trudno powiedzieć & 36.2 & 11.8 & 7.4 \\
\hline Nie & 38.3 & 32.0 & 20.6 \\
\hline Razem & 25.5 & 56.2 & 72.0 \\
\hline \% z ogółu & 100.0 & 1000.0 & 100.0 \\
\hline Stat. $\left(\mathrm{Chi}^{2}\right) ;$ ' $\mathrm{p}$ ' 47.527, df=4, p<0.01 & & 21.8 \\
\hline
\end{tabular}

Tak - suma odpowiedzi "zdecydowanie tak" i "raczej tak"; nie - suma odpowiedzi "zdecydowanie nie" i "raczej nie"

Chęć zmiany zawodu według oceny aktualnej pracy zawodowej. Przeważająca większość respondentów (83.0-98.9\%) z podgrupy A określiła swoją pracę jako nerwową, zagrażającą, gorączkową i niebezpieczną, podczas gdy w podgrupie $\mathrm{C}$ opinię taką wyraziło mniej respondentów (4.4-60.3\%). Ponad połowa osób $\mathrm{z}$ grupy A określiła swoją pracę jako 
nieprzyjemną, a co dziesiąty jako odrażającą, podczas gdy w grupie C zaledwie ok. 3\% badanych przyznało, że własna praca jest nieprzyjemna i nikt nie zgodził się z tym, że jest odrażająca. W obu podgrupach większość stwierdziła, że własna praca jest interesująca, ale nie jest ani uspokajająca, ani odprężająca (Tab. 5).

Tabela 5. Chęć zmiany zawodu według oceny aktualnej pracy zawodowej

\begin{tabular}{|c|c|c|c|c|c|c|c|c|c|}
\hline \multirow{3}{*}{\multicolumn{2}{|c|}{$\begin{array}{l}\text { Atrybuty prac } \\
\text { zawodowej lekarza }\end{array}$}} & \multicolumn{8}{|c|}{ y Deklaracja chęci zmiany zawodu w podgrupach (\%) } \\
\hline & & \multicolumn{3}{|c|}{$A(N=94)$} & \multicolumn{3}{|c|}{$\mathrm{B}(\mathrm{N}=153)$} & \multicolumn{2}{|c|}{$\mathrm{C}(\mathrm{N}=68)$} \\
\hline & & Tak & $\mathrm{Tp}$ & Nie & Tak & $\mathrm{Tp}$ & Nie & Tak & $\mathrm{Tp}$ \\
\hline \multicolumn{10}{|c|}{ Zalety pracy } \\
\hline 1 & Atrakcyjna & 29.8 & 30.9 & 39.3 & 69.3 & 10.5 & 20.2 & 67.6 & 17.6 \\
\hline 2 & Interesująca & 90.4 & 4.3 & 5.3 & 98.7 & 0.7 & 0.6 & 97.1 & 2.9 \\
\hline 3 & Uspokajająca & 1.1 & 6.4 & 92.5 & 2.6 & 4.6 & 92.8 & 2.9 & 14.7 \\
\hline 4 & Odprężająca & 2.1 & 1.1 & 96.8 & 2.6 & 4.6 & 92.8 & 10.3 & 10.3 \\
\hline \multicolumn{10}{|c|}{ Wady pracy } \\
\hline 5 & Gorączkowa & 84.0 & 10.6 & 5.4 & 90.2 & 7.2 & 2.6 & 33.8 & 22.1 \\
\hline 6 & Nerwowa & 98.9 & 1.1 & 0.0 & 98.7 & 1.3 & 0.0 & 60.3 & 13.2 \\
\hline 7 & Niebezpieczna & 83.0 & 9.6 & 7.4 & 63.2 & 15.6 & 21.2 & 4.4 & 22.1 \\
\hline 8 & Zagrażająca & 87.2 & 8.5 & 4.3 & 94.1 & 4.6 & 1.3 & 27.9 & 20.6 \\
\hline 9 & Nieprzyjemna & 55.3 & 42.6 & 2.1 & 0.0 & 11.8 & 88.2 & 2.9 & 7.4 \\
\hline 10 & Odrażająca & 12.8 & 40.4 & 46.8 & 0.7 & 2.6 & 96.7 & 0.0 & 4.4 \\
\hline
\end{tabular}

Tak - suma odpowiedzi "zdecydowanie tak" i "raczej tak"; tp - trudno powiedzieć, nie suma odpowiedzi "zdecydowanie nie" i "raczej nie"

Atrybuty nieprzyjemna i odrażająca $\mathrm{w}$ istotnym stopniu były związane $\mathrm{z}$ chęcią rezygnacji z zawodu. Największą siłę związku z chęcią pozostania w zawodzie wykazał atrybut atrakcyjna $($ rho $=0.409, \mathrm{p}<0.001)$.

W badanej grupie wyróżniono 3 zbiory respondentów z wartością sumarycznego indeksu oceny pracy zawodowej 0-2 (81 osób; 25.7\%), 3-4 (162; 51.4\%) oraz 5-10 (72; $22.9 \%$ ) przy współczynniku Alfa Cronbacha równym 0.67. Stwierdzono, że ok. 80\% osób z grupy A osiągnęło najniższą wartość indeksu, tj. 0-2. W grupie $\mathrm{C}$ równie wysoki odsetek lekarzy uzyskał wartość najwyższą, tj. 5-10 (Tab. 6).

Tabela 6. Chęć zmiany zawodu według sumarycznego indeksu oceny pracy zawodowej

\begin{tabular}{|l|l|l|l|l|}
\hline \multirow{2}{*}{$\begin{array}{l}\text { Sumaryczny } \\
\text { indeks oceny } \\
\text { aktualnej pracy } \\
\text { zawodowej }\end{array}$} & \multicolumn{4}{|l|}{ Deklaracja chęć zmiany zawodu w podgrupach oraz w całej próbie (\%) } \\
\cline { 2 - 5 } & $\mathrm{A}(\mathrm{N}=94)$ & $\mathrm{B}(\mathrm{N}=153)$ & $\mathrm{C}(\mathrm{N}=68)$ & $\begin{array}{l}\text { GRUPA } \\
\text { BADANA } \\
(\mathrm{N}=315)\end{array}$ \\
\hline $0-2$ & 79.8 & 3.3 & 1.5 & 25.7 \\
\hline $3-4$ & 20.2 & 85.6 & 17.6 & 51.4 \\
\hline $5-10$ & 0,0 & 11.1 & 80.9 & 22.0 \\
\hline
\end{tabular}




\begin{tabular}{|l|l|l|l|l|}
\hline \% z ogółu & 29.8 & 48.4 & 21.8 & 100 \\
\hline Stat. $\left(\mathrm{Chi}^{2}\right) ;$; $\mathrm{p}$ ' $350.973, \mathrm{df}=4, \mathrm{p}<0,001$ & \\
\hline
\end{tabular}

\section{DYSKUSJA}

Ponad połowa respondentów, bez różnicy płci, wskazywała na liczne wady swojej pracy i najczęściej (9 na 10 respondentów) na nerwowość. Atrybut nerwowości najczęściej łączył się w parę z gorączkowością. Osoby relatywnie młode, w wieku do 30 lat, częściej niż pozostałe zaznaczały atrybut nerwowa i nieprzyjemna, co wskazywałoby na to, że mają poważne zastrzeżenia do wykonywanej pracy. Respondenci pracujący w specjalnościach zabiegowych częściej niż pozostali potwierdzali atrybut odprężająca. Może to świadczyć o tym, że techniki i rytuały w specjalnościach zabiegowych mają wpływ na „warunkowanie ciała chirurga" (conditioning of the surgeon body) [16] i pozytywny wpływ na ocenę własnej pracy.

Ogólnie co piąty badany lekarz zadeklarował chęć zmiany zawodu, a co dwudziesty zdecydowaną chęć. Respondenci skłonni do zmiany zawodu odznaczali się niskim sumarycznym indeksem oceny pracy zawodowej, a więc in gremio potwierdzali wady pracy $\mathrm{i}$ zaprzeczali jej zaletom. Największą siłę związku z chęcią odejścia od zawodu wykazywały atrybuty pracy takie jak nieprzyjemna i odrażająca. Zarazem wybór atrybutu nieprzyjemna był częściej spotykany u lekarzy poniżej 30 roku życia. Można to uznać za sygnał, że młodzi lekarze stanowią grupę najbardziej skłonną do zmiany drogi kariery. Prawdopodobnie ma to związek z większą niż u starszych elastycznością wyborów życiowych. I nie musi to być związane $\mathrm{z}$ wypaleniem zawodowym, skoro $\mathrm{np}$. w USA wypalenie zawodowe występuje najczęściej w pokoleniu X (40-54 lata), a rzadziej wśród baby boomers (55-73 lata) i milenialsów (25-39 lat), tj. odpowiednio w 49\%, 39\%, 38\% danej grupy lekarzy [17].

Opisana sytuacja dotyczy roku 2018/19, a więc czasu przed pandemią COVID-19. W innym badaniu, wykonanym w Polsce $\mathrm{w}$ czasie pandemii uzyskano również alarmujące wyniki. Zaledwie $24 \%$ rezydentów i $36 \%$ specjalistów nie myślało nad decyzją odejścia z miejsca pracy, z zawodu, migracji za granicę lub ograniczenia aktywności zawodowej [8]. Jednocześnie mamy do czynienia $\mathrm{z}$ wieloletnią tendencją niedoboru i starzenia się kadry lekarskiej. Zgodnie z danymi Eurostatu Polska ma najmniejszą w UE liczbę praktykujących lekarzy na 1000 mieszkańców, tj. 2,4, przy średniej dla UE-27 wynoszącej 3,9 [18, 19], chociaż według innych źródeł liczba ta może wynosić od 3,4 do 4,4/1000 [20]. Według danych NIL w końcu grudnia 2021 r. zawód lekarza wykonywało w Polsce 145658 osób, w tym 60388 mężczyzn i 85270 kobiet. Mężczyźni w wieku emerytalnym ( $\geq 66$ lat) stanowili $33 \%$ praktykujących mężczyzn, a kobiety $\mathrm{w}$ wieku emerytalnym $(\geq 61$ lat $) \quad 21 \%$ praktykujących kobiet. W grupie najmłodszych lekarzy, w wieku do 35 lat, przypuszczalnie najbardziej skłonnych do zmiany kariery, mężczyźni stanowili $27 \%$ praktykujących mężczyzn, a kobiety 23\% praktykujących kobiet [21]. To kto nas będzie leczył, jeśli jedni i drudzy odejdą z zawodu, choćby niektórzy?

Nigdy wcześniej bolączki lekarzy nie zyskały tyle uwagi w światowym piśmiennictwie medycznym i mediach popularnych co w dobie pandemii COVID-19. Jeszcze przed epidemią w Wielkiej Brytanii jedna trzecia lekarzy, zwłaszcza medycyny ratunkowej i rodzinnych, demonstrowała wypalenie lub zespół wtórnego stresu pourazowego (secondary traumatic stress; STS) [22]. W USA w 2019 r. 44\% lekarzy, głównie kobiet, cierpiało z powodu wypalenia zawodowego, $11 \%$ miało potocznie rozumiane symptomy depresji (colloquially depressed), a 14\% myśli samobójcze [23, 24]. Jeszcze w lipcu 2020 r. w USA pisano, że graniczymy $\mathrm{z}$ utrwaleniem histerii wypalenia, co dodatkowo wzmacnia ambiwalentny lub negatywny stosunek do pracy i komplikuje życie lekarzy [25]. Ale pandemia COVID-19 zwiększyła wymagania wobec i tak już niedofinansowanych i 
przeciążonych systemów opieki zdrowotnej, a w konsekwencji zaostrzyła napięcia między profesjonalizmem a samopoczuciem lekarzy [26]. Badanie przeprowadzone wiosną $2021 \mathrm{r}$. wśród 1933 lekarzy w Wielkiej Brytanii dowiodło, że 78\% respondentów doświadczyło dystresu moralnego (moral distress), czyli niepokoju, który powstaje w wyniku sprzeczności między podejmowanym działaniem a jego oceną etyczną. Połowa badanych doświadczyła zaś urazu moralnego (moral injury), czyli szkód psychologicznych powstałych w wyniku długotrwałego dystresu [27]. Coraz powszechniejsze są głosy, że wsparcie dla pracowników systemu zdrowia stało się imperatywem [28,29].

Niniejsze badanie jest wstępnym rozpoznaniem sytuacji lekarzy, którzy byliby skłonni zmienić zawód. $Z$ powodów logistycznych badanie objęło próbę łatwo dostępną (convenience sample) z niewielką liczbą osób, zwłaszcza w młodym wieku, uczących się, w praktyce rezydentów, i zazwyczaj na początku kariery. Przedstawiono im do wypełnienia krótki kwestionariusz ankiety, ponieważ takie są oczekiwania lekarzy. Wysoki wskaźnik realizacji próby na poziomie $83 \%$ pokazał jednak żywe zainteresowanie lekarzy tematyką badania. Innym z ograniczeń była możliwość indywidualnej interpretacji atrybutów pracy, z tym jednak, że starano się minimalizować ten problem poprzez wgląd w rozszerzoną wykładnię. Jednak wyniki tego badania budzą niepokój i wskazują na pilną potrzebę prowadzenia dalszych badań, w tym jakościowych. Na podstawie takiej diagnozy możliwe będzie budowanie strategii wspierania lekarzy i utrzymania ich w zawodzie, a także całej polityki kadrowej systemu zdrowia.

\section{WNIOSKI}

1. Więcej lekarzy zgłaszało wady swojej pracy niż jej zalety. Zdecydowana większość lekarzy przyznała, że ich praca jest interesująca, ale zarazem nerwowa, zagrażająca i gorączkowa. Lekarze $\mathrm{w}$ wieku do 30 lat istotnie częściej uznawali swoją pracę za nerwową. Lekarze pracujący w specjalnościach zabiegowych istotnie częściej potwierdzali, że ich praca jest odprężająca.

2. Co piąty badany zadeklarował chęć zmiany zawodu. Chęć zmiany zawodu była silnie związana $\mathrm{z}$ ogólnie negatywną oceną własnej pracy, czyli potwierdzaniem jej wad i zaprzeczaniem zaletom.

3. Można oczekiwać, że w wyniku pandemii COVID-19 coraz więcej lekarzy będzie negatywnie oceniać swoją pracę, co może ich skłonić do zmiany zawodu. Sytuacja ta wymaga monitorowania wpływu COVID-19 na kadrę oraz podejmowania środków zaradczych i ochronnych.

\section{PIŚMIENNICTWO}

1. World Health Organization. Global strategy on human resources for health: Workforce 2030. World Health Organization, Geneva 2016: 10. https://apps.who.int/iris/bitstream/handle/10665/250368/9789241511131-eng.pdf

2. Huhtala M, Geurts S, Mauno S, et al. Intensified job demands in healthcare and their consequences for employee well-being and patient satisfaction: A multilevel approach. J Adv Nurs. 2021;77:3718-3732. https://doi.org/10.1111/jan.14861

https://onlinelibrary.wiley.com/doi/10.1111/jan.14861

3. Eurofund. Sixth European Working Conditions Survey - Overview report (2017 update), Publications Office of the European Union, Luxembourg 2017: 50. https://www.eurofound.europa.eu/sites/default/files/ef_publication/field_ef_document/ef1634en.pdf

4. Sirovich BE, Gottlieb DJ, Welch G, et al. Regional Variations in Health Care Intensity and Physician Perceptions of Quality of Care. Ann Intern Med2006 May 2;144(9):641-9. 
5. Visser MRM, Smets EMA, Oort FJ, et al. Stress, satisfaction and burnout among Dutch medical specialists. CMAJ. $2003 \quad$ Feb $4 ; \quad 168(3): \quad 271-275$. https://www.ncbi.nlm.nih.gov/pmc/articles/PMC140468/

6. Labarda MP. Career shift phenomenon among doctors in tacloban city, philippines: lessons for retention of health workers in developing countries. Asia Pacific Family Medicine 2011;10:13. https://apfmj.biomedcentral.com/articles/10.1186/1447-056X-10-13

7. Medscape Physician Nonclinical Careers Report 2021. https://www.medscape.com/slideshow/2021-nonclinical-careers-6014472

8. Buchelt B, Iwona Kowalska-Bobko I, Masłyk T. Ostatni zgasi światło. Nastroje polskich lekarzy w postpandemicznej rzeczywistości. Małopolska Szkoła Administracji Publicznej Uniwersytetu Ekonomicznego w Krakowie.. Kraków, grudzień 2021: 20. https://politykipubliczne.pl/wp-content/uploads/2021/12/31.-Raport_Ostatni-zgasi-swiatlo.pdf

9. AMA (Victoria). Alternate career paths for doctors. https://amavic.com.au/careersadvice/career-resources/alternate-career-paths-for-doctors

10. Solecki L, Klepacka P. Przyczyny oraz czynniki sprzyjające występowaniu zespołu wypalenia zawodowego wśród lekarzy zatrudnionych w publicznych sektorach opieki zdrowotnej. Med Srod. 2017;20(1):7-16. http://www.environmed.pl/Przyczyny-oraz-czynniki-sprzyjajace-wystepowaniuzespolu-wypalenia-zawodowego-wsrod,112952,0,1.html

11. Baliński P. Mapy potrzeb zdrowotnych - Baza Analiz Systemowych i Wdrożeniowych. Ile pracują lekarze i lekarze dentyści w Polsce?-Warszawa, marzec 2018. https://nil.org.pl/uploaded_files/1575629838_mapy-zdrowia-2017-streszczenie-raportu.pdf

12. Naczelna Izba Lekarska. Instytut Filozofii I Socjologii PAN. Nasza praca 2018. Raport z badania wśród lekarzy i lekarzy dentystów. Warszawa, grudzień 2018 roku.

https://nil.org.pl/uploaded_files/1575629903_osai-ifis-obpis-nasza-praca-2018-raport.pdf

13. Makara-Studzińska M, Tylec A, Kudlik A, i wsp. Analiza zjawiska wypalenia zawodowego w grupie lekarzy psychiatrów - przegląd badań. Psychiatria 2018; 15(1): 35-38. https://journals.viamedica.pl/psychiatria/article/view/56545

14. Makara-Studzińska M, Wontorczyk A, Izydorczyk B. Stress and occupational burnout in a population of Polish doctors - Organizational-professional and non-professional-social predictors. AAEM 2020; 27(3):456-468.

15. Naczelna Izba Lekarska. Opinie o pracy zawodowej, proteście lekarzy i cyfryzacji w ochronie zdrowia Raport $\mathrm{z}$ badania opinii środowiska lekarskiego. Warszawa, maj $2018 \mathrm{r}$. https://nil.org.pl/uploaded_files/1575629728_osai-obpis-sondaze2018-raport-final-v2.pdf

16. Marini M. Unproductive Participation and Protection Against Germs: Technical-Ritualistic Practices in Heart Surgery. Vibrant, Virtual Braz. Anthr. 16 • 2019 • https://doi.org/10.1590/180943412019v16d604 https://www.scielo.br/j/vb/a/yhQcCq8tzSvTFNXQpp7qsfC/?lang=en\&format=pdf

17. Medscape National Physician Burnout \& Suicide Report 2020: The Generational Divide https://www.medscape.com/slideshow/2020-lifestyle-burnout-6012460?faf=1

18. OECD. Health at a Glance: Europe 2020 : State of Health in the EU Cycle. Availability of doctors. https://www.oecd-ilibrary.org/sites/1d767767en/index.html?itemId=/content/component/1d767767-en

19. OECD, World Health Organization. State of Health in the EU. Poland. Country Health Profile 2021. 13 December 2021. https://eurohealthobservatory.who.int/publications/m/poland-countryhealth-profile-2021 
20. Kowalska-Bobko I, Gałązka-Sobotka M, Zabdyr-Jamróz M, et al. Sustainability and Resilience in the Polish Health System. London School of Economics and Political Science, March 2021:38. https://www3.weforum.org/docs/WEF_PHSSR_Poland_Report.pdf

21. Naczelna Izba Lekarska. Zestawienie liczbowe lekarzy i lekarzy dentystów wg wieku, płci i tytułu zawodowego. 2022.01.03. https://nil.org.p1/uploaded_files/1641220880_za-grudzien-2021zestawienie-nr-03.pdf

22. McKinley N, McCain RS, Clarke M, et al. Resilience, burnout and coping mechanisms in UK doctors: a cross-sectional study. BMJ Open 2020;10:e031765. doi:10.1136/ bmjopen-2019-031765 https://bmjopen.bmj.com/content/10/1/e031765

23. Medscape National Physician Burnout, Depression \& Suicide Report 2019. https://www.medscape.com/slideshow/2019-lifestyle-burnout-depression-6011056

24. Kalmoe MC, Chapman MB, Gold JA, Andrea M. Giedinghagen AM. Physician Suicide: A Call to Action. Mo Med. 2019 May-Jun; 116(3): 211-216. https://www.ncbi.nlm.nih.gov/pmc/articles/PMC6690303/

25. Sotile WM, Fallon R, Orlando J. et al. Burnout Hysteria With Self-Compassion: A Key to Physician Resilience. Journal of Pediatric Orthopaedics: July 2020 - Volume 40 - Issue - p S8-S12 doi: 10.1097/BPO.0000000000001503

https://journals.lww.com/pedorthopaedics/Fulltext/2020/07001/Curbing_Burnout_Hysteria_With_Self _Compassion_A.4.aspx

26. Goddard AF, Patel M. The changing face of medical professionalism and the impact of COVID-19. The Lancet 2021; 397(10278): 950-952. DOI:https://doi.org/10.1016/S01406736(21)00436-0 https://www.thelancet.com/journals/lancet/article/PIIS0140-6736(21)004360/fulltext

27. British Medical Association. Moral distress and moral injury. Recognising and tackling it for UK doctors. 2021: 2. https://www.bma.org.uk/media/4209/bma-moral-distress-injury-survey-reportjune-2021.pdf

28. Delaney RK, Locke A, Pershing ML, et al. Experiences of a Health System's Faculty, Staff, and Trainees' Career Development,Work Culture, and Childcare Needs During the COVID-19 Pandemic. JAMA Network Open. 2021;4(4):e213997. doi:10.1001/jamanetworkopen.2021.3997

29. House of Commons. Health and Social Care Committee Workforce burnout and resilience in the NHS and social care Second Report of Session 2021-22. Report, together with formal minutes $\begin{array}{llllll}\text { relating to } & 18 \text { Me } & \text { May }\end{array}$ https://committees.parliament.uk/publications/6158/documents/68766/default/ 